\title{
Banks consider doctors up for grabs after MD Financial Management sale
}

\author{
Cite as: CMAJ 2019 May 13;191:E548-9. doi: 10.1503/cmaj.109-5749
}

Posted on cmajnews.com on Apr. 25, 2019.

$\mathrm{T}$ he sale of MD Financial Management to Scotiabank last year has touched off a competition among Canada's major banks to attract physician customers, with several launching investment and business packages in recent months aimed at health care professionals.

In December, TD Bank announced a wealth management service for health care professionals, to be paired with its existing products for business and personal banking aimed at doctors and medical students. In March, Scotiabank and $\mathrm{CIBC}$ both launched similar packages.

Glen Gowland, executive vicepresident of global wealth management at Scotiabank, says the acquisition of MD from the Canadian Medical Association (CMA) has allowed the bank to draw upon MD's 50 years of experience working with doctors to build a suite of options that address the needs of doctors at every stage of their careers. Scotiabank is pitching the new products as a way for doctors who manage their investments through $M D$ to bring all their banking services under one umbrella. "It allows them to maintain their valuable relationship with MD and add in banking services that are tailored and driven by MD's experience over the years," says Gowland.

But other banks also saw the sale of $M D$ as an opportunity, especially given the strong negative reaction among many doctors when it was announced. Many clients of MD indicated they would take their business elsewhere, opening up a lucrative part of the market that had long been difficult for banks to crack. "On social media you saw the displeasure with how the CMA handled the sale," says Andrew Turnbull, senior vice-president of business banking at CIBC. "That disruption created an opportunity for us to position ourselves."

CIBC has long offered banking services for medical students, and its new package of integrated business and personal banking, along with investment services, is a natural extension of that, says Turnbull.

It is not only the big banks that are seeing that opportunity. Small independent firms are also hoping to benefit from the change, says Markus Muhs, an investment advisor in Edmonton with Canaccord Genuity Wealth Management. "My whole career l've struggled to compete with MD. They seemed to have a unique connec- tion with doctors," he says. "Now I am seeing doctors shopping around because of the change in ownership."

Now that MD is no longer owned by the CMA, doctors are less likely to sign up with them automatically, says Muhs. "It will be less of a sure thing; they're not the default anymore," he says. Some independent advisors are already starting to target physicians as a valuable niche market.

Dr. Paul Healey, an emergency doctor in Oakville, Ontario, says he has seen a huge spike in interest in the Physician Financial Independence discussion group he runs on Facebook. Membership in the

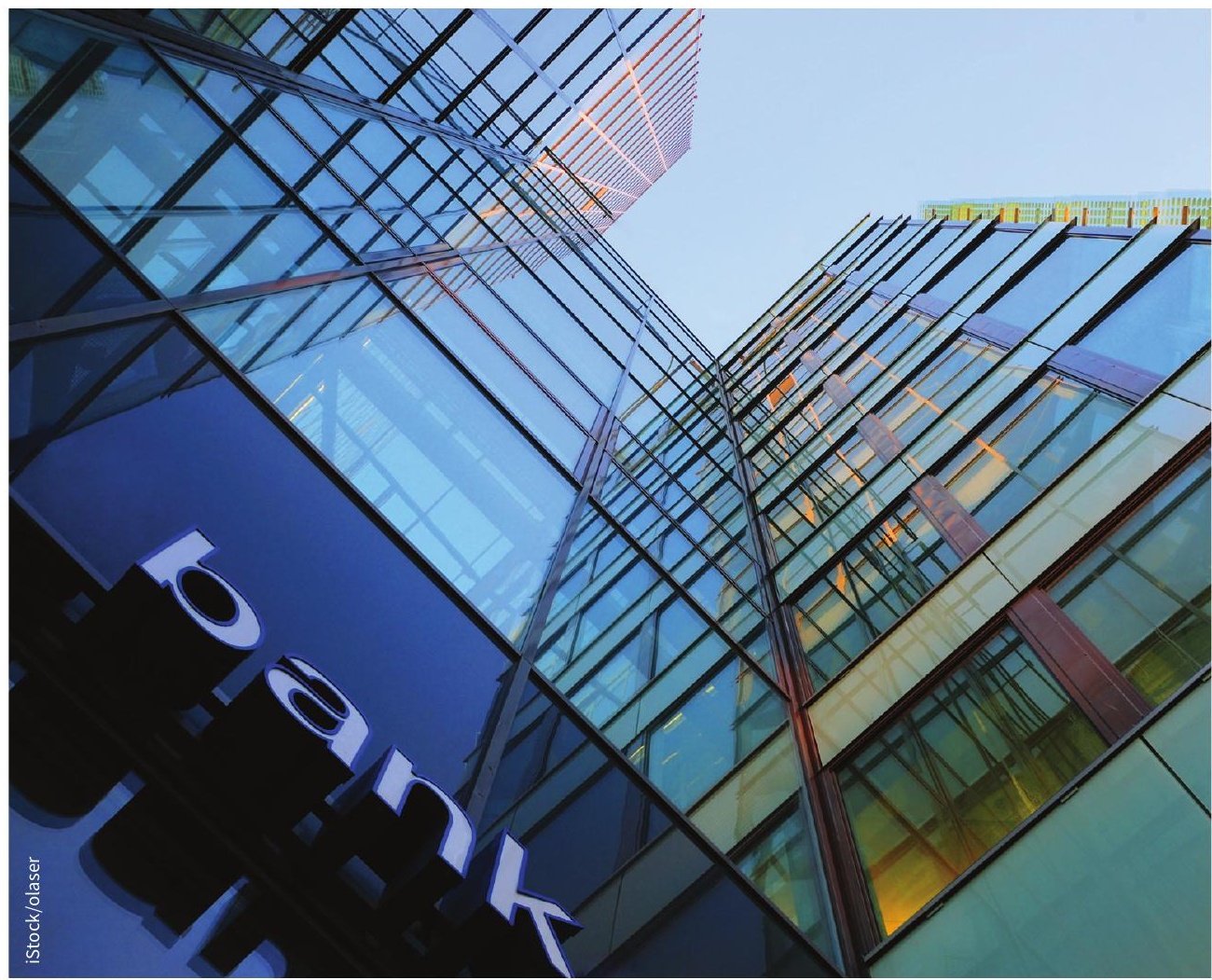

Canadian financial institutions are creating services targeting doctors. 
group, which focuses on self-managed and low-cost investing, has doubled to around 11000 since the sale of MD last year. "After the sale, many doctors realized MD was not the best group to be with in the first place," he says. "There is now a lot more interest in self-management or low-cost alternatives like Wealthsimple or Questrade."
The Ontario Medical Association is also developing a retirement investment plan for its members, which it plans to launch in September, says Healy, who is a member of the board designing the plan. "They are pushing into this space as well."

But despite the sense among investment professionals that MD is no longer the automatic choice for physicians, doctors are not leaving the company in droves, says Gowland. And the company's assets are still growing; MD recently passed the milestone of $\$ 50$ billion under management. "It shows that people are happy with the organization," says Gowland.

Brian Owens, St. Stephen, NB 